\title{
CORRECTION
}

Open Access

\section{Correction to: Isolation and identification of Candida spp. from immunocompromised patients}

Anas Salama Sayed Hemaid ${ }^{1 *}$, Mohamed Mahmoud Efat Abdelghany ${ }^{2}$ and Tarek Mohamed Abdelghany ${ }^{1}$

\section{Correction to: Bull Natl Res Cent (2021) 45:163 https://doi.org/10.1186/s42269-021-00620-z}

Following the publication of the original article [1], the authors notified an error in the affiliation list.

The wrong list currently read:

Anas Salama Sayed Hemaid ${ }^{1 "}$, Mohamed Mahmoud Efat Abdelghany ${ }^{2}$ and Tarek Mohamed Abdelghany ${ }^{2}$

The correct list should read:

Anas Salama Sayed Hemaid ${ }^{1 *}$, Mohamed Mahmoud Efat Abdelghany ${ }^{2}$ and Tarek Mohamed Abdelghany ${ }^{1}$

\section{Author details}

${ }^{1}$ Botany and Microbiology, Faculty of Science, Al-Azhar University, Cairo, Egypt. ${ }^{2}$ Microbiology and Immunology Department, National Research Center, Dokki, Giza, Egypt.

Published online: 24 November 2021
Reference

Hemaid et al (2021) Bull Natl Res Cent 45:163. https://doi.org/10.1186/ s42269-021-00620-z

\section{Publisher's Note}

Springer Nature remains neutral with regard to jurisdictional claims in published maps and institutional affiliations.

*Correspondence: anas_hemaid@yahoo.com

${ }^{1}$ Botany and Microbiology, Faculty of Science, Al-Azhar University, Cairo,

Egypt

Full list of author information is available at the end of the article 